\title{
ŞAN TEKNIĞiNDE DOĞRU NEFES ALMANIN ÖNEMI
}

\author{
Öğr. Gör. Tülay UYAR*
}

\section{ÖZET}

Kaynak tarama modeli ile yapılan bu çalışmada şan tekniğinde doğru nefes almanın önemi ve doğru nefes almanın şan tekniğine olan katkısı araştırılmaktadır.

Güzel şarkı söylemek ve kaliteli bir ses çıkarabilmek için iyi bir nefes tekniğine sahip olmak gerekmektedir. İyi nefes kullanma tekniği, çıkarılan sesin kalitesini, tonunu, entonasyonunu ve gürlüğünü belirlemektedir. Doğru nefes almak ve bu nefesi kontrollü bir biçimde sürdürebilmek için şancıların bu konuda çalışma ve egzersiz yapmaları büyük önem taşımaktadır.

Kaynak tarama modeli ile yapılan bu çalışma, şan pedagoglarına ve şan eğitimi alan öğrencilere nefes alma ve kullanma tekniklerinin, şan tekniğine olan katkıları açısından yol gösterici olması amacı taşımaktadır.

Anahtar Kelimeler: Şan Tekniği, Nefes Tekniği, Ses

* Istanbul Üniversitesi, Devlet Konservatuvarı, Sahne Sanatları Anasanat Dalı, İstanbul / TÜRKIYYE tulayuyar@gmail.com 


\title{
THE IMPORTANCE OF GOOD BREATHING IN SINGING TECHNIQUE
}

\author{
Lect. Tülay UYAR*
}

\section{ABSTRACT}

This article utilizing literature review model focuses on the breathing technique in singing and its contribution to singing technique.

Having a good breathing technique is crucial to sing beautifully and produce a good quality of voice. Good breathing technique controls the quality of the sound, the tone, the intonation and the volume. Therefore, it is essential for singers to do breathing exercises in order to breath efficiently and maintain breath control.

This article aims to provide guidance about the breathing techniques and its contribution to singing technique for singing teachers and for tstudents at the opera department at the conservatories.

Key Words: Singing Technique, Breathing Technique, Voice

* Istanbul University, School of Music and Drama, Performing Arts, İstanbul / TURKEY tulayuyar@gmail.com 


\section{GíRİş}

Ses eğitimi, şan eğitimi olarak adlandırılmaktadır. Şan kelimesi dilimize Fransızca 'Chant' 'şarkı söylemek' kelimesinden geçmiştir. Şarkı söylemenin yüzyıllar boyunca onlarca farklı tarzı olmuştur. Güzel şarkı söyleyebilmenin ilk adımı iyi bir nefes almakla başlar. Bir şan sanatçısının enstrümanı olan bedenin rahatlı̆̆ çok önemlidir. Derin ve iyi alınmış nefes, çıkarılan sesin kalitesini ve şan tekniğinin seviyesini belirler.

"Her sanat dalı teknik, mekanik ve estetik bölümlerden oluşmaktadır. Birinci bölümdeki zorlukların üstesinden gelemeyen bir şarkıcı, ikinci bölümde asla mükemmeliyete ulaşamayacaktır. Hatta bir dahi olsa bile." Mathilde Marchesi ${ }^{1}$ (Miller, 2004, s.1).

Bu makalede, sesin oluşumu, güzel ve kaliteli ses çıkarabilmek için gerekli olan nefes ve nefes alma teknikleri araştırılmıştır. Bu bağlamda, doğru şan tekniği ve doğru nefes alma konusunda birçok kitabı bulunan ve bu konuda ilk bilimsel çalışmaları yapmış olan Manuel Garcia'dan başlayarak günümüz yazarlarına dek nefes tekniği ile ilgili yazılmış belgeler ve kitaplardan yararlanılmıştır.

\section{Yöntem}

$\mathrm{Bu}$ araştırma nitel bir araştırma olup doküman incelemesi modeli kullanılarak yapılmıştır. "Doküman incelemesi, araştırılması hedeflenen olgu veya olgular hakkında bilgi içeren yazılı materyallerin analizini kapsar” (Yıldırım, Şimşek, 2006, s.187). Araştırma yapılırken doküman inceleme aşamaları tek tek gerçekleştirilmiştir. Forstere göre (1995, Akt, Yıldırım ve Şimsek, 2006) doküman inceleme aşamaları beş bölüme ayrılmaktadır. Bu çalışmada kaynak taranırken ve dokümanlar incelenirken bu aşamalar uygulanmıştır.

Dokümanlara ulaşma aşaması: Araştırma konusu belirlendikten sonra şarkı söylemede doğru nefes almanın önemi hakkında kaynaklara ulaşılmıştır.

Orijinalliğin kontrol edilme aşaması: Konu hakkında elde edilen dökümanların orijinal olup olmadığı yine derinlemesine bir araştırma ve kütüphane yardımı ile gerçekleştirilmiştir.

Dokümanları anlama aşaması: Elde edilen bulgular ve dokümanlar ayrı ayrı incelenerek anlama aşaması gerçekleştirilmiştir. Her kaynaktan belirli önem sırasına göre notlar tutularak diğer kaynaklarla ilişkisi olup olmadığı kontrol edilmiştir.

Veriyi analiz etme aşaması: Konu ile ilgili diğer aşamalar sonucunda elde edilen veriler analiz edilmiştir. Analiz aşamasında karşılaşılan ve anlaşılmayan yerler uzman kişilere sorularak çözümlenmesi sağlanmıştır.

\section{Ses nasıl oluşur?}

Ses çıkarmadan önce yaptığımız eylem nefes almaktır. Müzikal bir ses çıkarmak üç bölümden oluşmaktadır. Bu üç ana bölüm, güç kaynağı, titreşim ve rezonatör olarak adlandırılmak-

1 Dünya çapında meşhur olmuş birçok opera sanatçısı yetiştirmiş şan duayeni Matilde Marchesi, 1854 yılında ilk kez laringoskopu icat eden bariton Manuel Garcia’nın öğrencisidir. 
tadır. Güç kaynağı akciğerlerimizdir. Titreşimi (vibrasyonu) sağlayan ses kutusu olarak bilinen organımız gırtlaktır(larenks). Rezonatör bölgelerimiz ise boğaz, burun, ağız ve sinüslerimizdir. "İnsan sesinin oluşumu için güç kaynağı, titreşim ve rezonatör gereklidir. İnsan sesinin üretimi için gerekli güç kaynağı havadır. Vibrasyonu, titreşimi sağlayan organlarımız ses kaslarımızdır. Rezonatör bölgelerimiz ise boğaz, burun boşluğu, ağız, sinüslerdir” (Smith, 2007, s.13).

Sesin kuvveti aldığımız nefesle doğru orantılıdır. İyi bir ses üretebilmek için iyi nefes almak gerekir. "Beynin motor korteksindeki bir dizi itki üretilir ve sinir sistemi aracılığıyla konuşma yapılarına (konuşma merkezi) doğru gönderilir. Bu itkiler, bedenin çeşitli yerlerine, yumuşak ve uyumlu hareketlerin meydana gelmesini sağlayacak biçimde varmak üzere zamanlanır. İlk önce dudaklar ve burundan akciğerlere kadar olan ses sistemi açılır; havanın akciğerlere nispeten engellenmeden dolmasını sağlamak amacıyla, göğüs bölgesindeki basıncı azaltmak için, solunum kasları kasılır. İstenilen ses için gerekli olan yeterli miktardaki hava ciğerlere alındığında, solunum sistemi işlemleri tersine çevirir, şişirilmiş dokunun esnek bir biçimde geri çekilmesi ve hem karın hem de gögüs kaslarının kasılmasıyla oluşan güç, havayı ses sistemine göndererek, ağız ve burun yoluyla dışarı doğru iter (Linklater, 1976, s.16-17[L. Suner: Ses ve Oyuncu]). "Nefes aldığımız zaman, diyafram kası aşağı iner, göğüs kafesi genişler ve hava akciğerlere girer. Nefes verdiğimizde bu işlemin tersini meydana getirerek, akciğerlerden nefes borusunda (trakea) bir hava akımı yaratarak çıkar. Bu hava akımı, ses kaslarının gırtlakta (larenkste) ses üretimi için gerekli gücü sağlamaktadır. Ne kadar kuvvetli bir hava akımı olursa, o kadar kuvvetli ses oluşmaktadır." (2015, American Academy of Otolaryngology).

Ses üretimi için gerekli olan ikinci adım titreşimdir. Sesin titreşimi ses tellerinde oluşur. "Gırtlak (larenks), yukarı doğru çıkan hava akımını biraz engellemek için ses tellerini kısmen kapatmıştır. Esnek ses telleri aralarından hava geçerken hemen senkronize bir biçimde titreşmeye başlar. Bu titreşimler, yukarıdaki ses sistemine giden hava akımını hava kümeciklerine böler. Bu hava kümecikleri yutaktaki (farenks) havayı harekete geçirirler ve üst ses sistemimizde sesi üretirler" (Linklater, 1976, s.16-17 [L. Suner: Ses ve Oyuncu]).

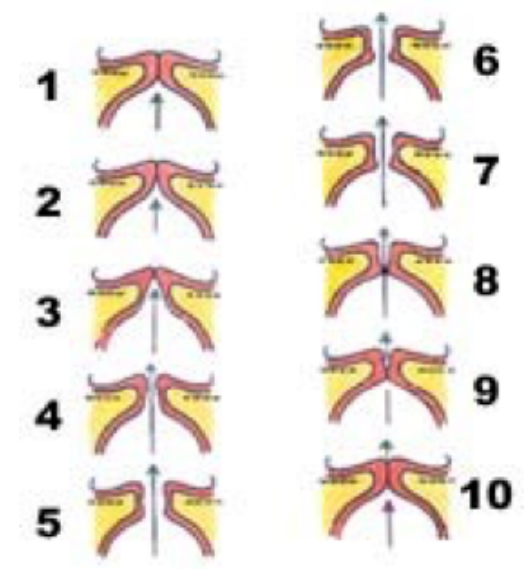

Şekil 1. Ses kaslarının (vocal fold) vibrasyon strasindaki hareket diyagramı (voicefoundation.org, Erişim Tarihi: 03/02/2017). 
"Ses kaslarının titreşim sırasındaki ilk hareketinde (Şekil 1, n.1), ses kasları kapalı pozisyonda iken, hava akımı yukarı doğru çıkar. Daha sonraki (Şekil 1, n.2,3) aşamada hava akımı, ses kaslarının alt tarafındaki titreşim bölgesini açar. Hava akımı yukarı doğru ses kaslarının üst tarafına çıkmaya başlar ve ses kaslarını aralar. (Şekil 1, n.4,5). Hızlı hava akımının gerisinde oluşan düşük basınç, Bernoulli hareketinin oluşmasını sağlar. Böylelikle ses kaslarının alt tarafı kapanırken üst tarafı açılır (Şekil 1, n.6-10). Ses kaslarının kapanışı ile hava akımı kesilir” (Şekil 1, n.10) (voicefoundation.org). "Fonasyon sırasında, ses kasları birleşir. Hava ses kaslarının altından yukarıya çıktıkça, ses kasları havanın baskısıyla birbirlerinden ayrılır. Ayrıldıkları zaman hava geçer ve sonra tekrar birleşirler. Bu eylem fizikte Bernoulli hareketi olarak bilinmektedir. Bernoulli hareketi iki cismin arasından havanın geçmesiyle çekilme hareketidir. Fakat fonasyon sırasında ses kaslarında kapanma ve açılma hareketi olmamaktadır. Ses kasları hep birleşiktir fakat havanın geçmesiyle birlikte saniyede birçok kez birbirlerine değip, ayrışarak titreşirler.” (Smith, 2007, s.15).

Ses üretiminin üçüncü aşamasında rezonatör bölgeleri devreye girmektedir. "Rezonatörlerin şekli, hacmi ve açıklığı, sesin temel tondan daha yüksekte bulunan yapısını (sesin armonik yapısı) belirlerken, temel ses perdesi, ses tellerinin titreşme hızı tarafından belirlenir. Rezonansın iki türlü olduğu düşünülebilir. Birincisi, amaçlanan konuşma sesi hiç göz önünde bulundurulmaksızın, gırtlakta oluşturulan sesi şekillendirmek ve renklendirmek için kullanılır. İkincisi ise, girtlakta üretilen sesi belirli bir konuşma sesine dönüştürür. Birinci tür ses her zaman konuşmacıda mevcuttur. İkincisi ise konuşmacının ne demek istediğine bağlıdır. Buna bağlı hareketler artikülasyonu oluşturur" (Linklater, 1976, s.16-17 [L. Suner: Ses ve Oyuncu]).

\section{Nefes alma ve nefes alma sirasında kullanılan organlar}

Nefes alma sinyali beynimize iletilir. Beynimize ulaşan sinyalle nefes alma işlemi başlar. "Beynimize ne kadar oksijen ihtiyacımız olduğu ile ilgili sinyaller ulaşmaktadır. Ne kadar oksijen ihtiyacımız olduğu ne kadar aktif olduğumuzla ilgilidir. Örneğin, uyurken, bir yere koştuğumuz zamankine göre daha az oksijene ihtiyaç duyarız bu sebeple yavaş nefes alıp veririz. Beynimiz, ne kadar oksijen ihtiyacımız olduğunu anladığı zaman, nefes alıp verme sırasında kullanılan kaslara sinirler aracılığıyla mesaj iletir. Sinirler, nefes alma sırasında kullanılan kaslara nefes almasını söylediği zaman diyafram kası düzleşir. Aynı zamanda, göğüs kafesi yana ve yukarı doğru genişler. Böylece akciğerler, nefesi içeri almak için gerekli genişlikteki alana sahip olur" (blf.org.uk, Erşim Tarihi: 12/01/2017). 


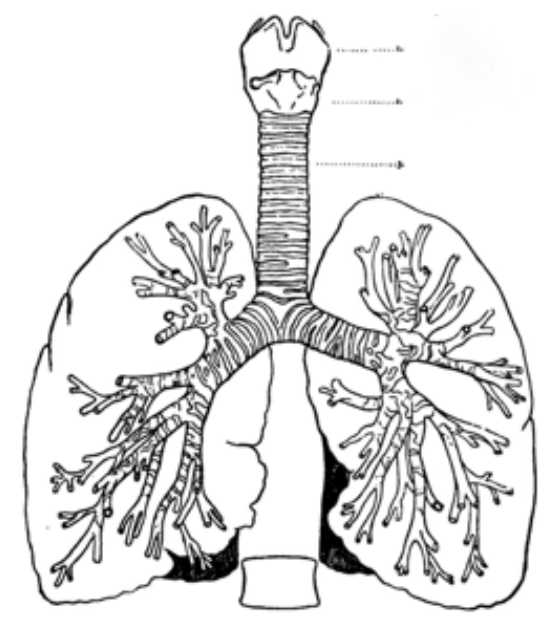

Şekil 2. Akciğerler, Nefes Borusu (Trakea), Gırtlak (Larenks)

\section{Troid Kıkırdak (Kalkansı kıkırdak )}

\section{Krikoid kıkırdak}

3. Nefes Borusu (Trakea) (Garcia, 1894: 3).

"Nefes aldığımız zaman, hava ağız veya burundan içeri girerek, boğazdan ve nefes borusundan aşağı iner. Nefes borusu, bronş olarak adlandırılan, biri sağ ciğere, diğeri ise sol ciğere giden iki adet hava borusuna ayrılır. Hava bronşlardan geçer. Bronşlar 15 ila 25 arasında bronşcuklar olarak adlandırılan küçük hava yollarına ayrılır. Bronşcuklardan geçen hava alveollere ${ }^{1}$ ulaşır. Nefes verme işlemi ise diyafram ve kaburgaların arasındaki kasların gevşemesi ile gerçekleşir. Bu şekilde hava (karbondioksit) dışarı atılır ve akciğerler eski haline geri döner" (blf.org.uk, Erşim Tarihi: 12/01/2017).

Şarkı söylerken güçlü ve kaliteli bir ses üretebilmek için abdominal, diyaframa dayalı nefes almak gerekmektedir. Diyafram, nefes alırken kullanılan ana kastır. Kubbe şeklinde olan diyafram, solunumun ana görevini gören kastır. Güçlü ve kaliteli bir ses çıarmak için diyafram kasının aktive olması gerekmektedir. Diyafram, göğüs boşluğunu, karın boşluğundan ayırmaktadır. Diyafram nefes aldığımızda kasılır ve düzleşir, nefes verdiğimizde ise genişler ve kubbe şeklini alır. "Nefes alıp verme işlemi solunumu oluşturur. Akciğerler solunum organlarıdır ve ses çıkarmak için gerekli olan havayı barındırırlar. Akciğerlere alınan hava, ağız, burun, yutak(farenks), glotis(nefes borusu ağzı) ve soluk borusuna iletilir. Solunumu nefes alma ve nefes verme işlemi oluşturmaktadır. Akciğerler, diyafram ile birlikte göğüs kafesinde bulunurlar. Diyafram kası solunumdaki en önemli kastır ve göğüs kafesinin alt kısmında yer alır. Kubbe şeklindedir ve solunumu kendi kontrolü altında gerçekleştirir” (Garcia, 1894, s.3-4).

2 Alveol: Akciğerlerde gaz değişiminin yapıldığı çok ince duvara sahip hava kesesi. 


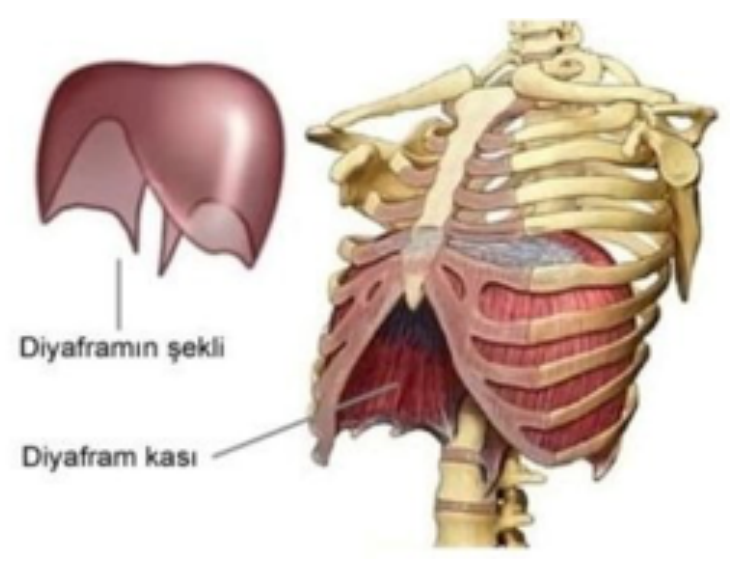

Sekil 3. Diyafram Kasının Şekli

(www.msxlabs.org, Erşim tarihi: 20/01/2017)

Yaşadığı dönemde dünyaca ünlü bir çok sanatçı ve şan pedagogu yetiştirmiş bariton Manuel Garcia Hints on Singing adlı kitabında diyaframı şu şekilde yazmaktadır. "Diyafram nefes almayı kontrol eder. Ses çıkarmak için diyafram kendini düzleştirir, mide hafifçe genişler ve nefes burundan, ağızdan veya her ikisinden aynı anda alınır. Abdominal yani karına alınan bu nefes alma sırasında kaburgalar oynamaz, akciğerler de bütün kapasitesi kadar dolmaz ve diyafram kasılır. Ancak bundan sonra, gögüs kafesi yükselir ve karın genişler. Bu nefes alma tekniğinde, akciğerler yana, arkaya ve öne doğru serbest hareket edebilmektedir. Bu nefese torakal (göğüse ait) nefes denilmektedir. Bu nefesi yavaş ve derin bir biçimde almak gerekmektedir” (Garcia, 1894, s.4-5).

\section{Kaliteli ve güzel ses üretiminde iyi nefesin almanın önemi}

"Kim iyi nefes almayı ve iyi telaffuz etmeyi biliyorsa, iyi şarkı söylemeyi biliyor demektir." Pachiarotti. (Shakespeare, 1898, s.15).

Kaliteli ve güzel bir ses çıkarabilmek için, bir şancının enstrümanı olan bedenin çok rahat olması gerekmektedir. Aynı zamanda, iyi ve derin bir nefes almak ve bu nefesin kontrolünü sağlamak gereklidir. 1849-1931 yılları arasında yaşamış olan, Londra’da Royal Academy of Music profesörlerinden, İngiliz tenor John William Thomas Shakespeare The Art of Singing adl kitabında şarkı söylerken gerekli olan nefes tekniği ile ilgili önemli bilgiler vermektedir. "Nefes çok iyi biçimde kontrol ediliyorsa, dil çok rahat bir pozisyonda ise ve telaffuzunuz iyi ise doğru şekilde şarkı söylüyorsunuz demektir” (Shakespeare, 1898:15). Shakespeare The Art of Singing kitabında, bir şarkıcının kaliteli ve güzel ses çıkarabilmesi için kaliteli bir nefese ihtiyacı olduğundan bahsetmektedir. Shakespeare kitabında, "Omuzlarımızın elastikiyetini kaybetmeden, serbest biçimde alabildiğimiz kadar derin bir nefes almalıyız" demektedir (Shakespeare, 1898, s.11).

Ustaca şarkı söylemek için nefesi ustaca kullanmak gereklidir. Nefes ile desteklenen bir ses, iyi bir şarkıcının özelliklerindendir. İyi bir şarkıcının nefesini çok iyi kontrol edebilmesi ge- 
rekmektedir. "İtalyancada nefes kontrolüne appoggio denilmektedir. Appoggio, sesin desteği demektir. Nefese yaslanmak anlamına gelmektedir. İyi bir şarkıcı, kuvvetli bir biçimde nefesi dışarı verdiğinde bile, içinde hala hava bulundurmaktadır” (Shakespeare, 1898, s.22).

"Appoggio nefes tekniği, dar bir perspektiften bakılarak sadece şarkı söyleme sırasında hava akışının idare edilmesi demek değildir. Appoggio, yapısal desteğin bütün sistemini kapsamaktadır" (Miller, 2004, s.5).

Crescentini; "Şarkı söyleme sanatı için, boynun rahatlığı ve sesin nefesin üzerinde olması gerekmektedir" demektedir. "Boyun ve boynun; boğaz, dil, çene gibi herhangi bir parçası sıkışık olmamalı, bedenin içinde larenkse ulaşan nefes kontrollü olmalı ve söylenilen nota, sanki nefesin üzerinde dinleniyor şeklinde hissedilmelidir" (Shakespeare, 1898, s.15). Doğru nefes kontrolü, girtlak ve dil rahatlığı olmadan, mükemmel şarkı söylemek mümkün değildir. Nefes kontrolü, boyun ve dil rahatlığı ile sesin nefes üzerinde kayması mümkün olmaktadır” (Shakespeare, 1898, s.15).

Eski İtalyan Ekolü şarkı söyleme tekniğinde, nefes çok önemlidir. Bu teknikte, önce ses başlar ve nefes ardından gelir. "Eski İtalyan Ekolünün duayen şan pegagogları iki çeşit nefes öğretmişlerdir; Uykumuzda kullandığımız, abdominal nefes denilen diyaframın kasının harketiyle oluşan, abdominal duvarın çıkmasıyla ve düşük göğüsle oluşan nefes. Diğeri ise, bir performans sırasında hazırlanarak aldığımız nefes. Bu nefes, sahip olduğumuz bedenle sağlanan, yüksek ve süreklilik gerektiren miktarda bir gerginlik gerektiren bir nefestir. Eski İtalyan Ekolünün pedagogları ikinci tür nefesin şarkı söylemek için daha uygun olduğunu düşünmüşlerdir. Çünkü şarkı söylemek desteklenmesi gereken bir enerjiye ihtiyaç duymaktadır. Bu şekilde hiç güç gerektirmeyen doğal bir ses ortaya çıkmaktadır. Bu tarz nefeste, diyafram, fiziksel anatomik kurallar dahilinde otomatik olarak hareket etmektedir." (Bloem-Hubatka, 2012, s.38-39). "Fakat günümüz şan tekniği için gerekli olan nefes tekniğinde, uykumuz sırasında aldığımız nefesin, şarkı söylerken kullanmak için daha uygun olduğu düşünülmektedir. Uyku sırasında, fiziksel bir pasiflik halinde oluruz. Genişlemiş göğüs ve gergin bel ile ele ele giden fiziksel aktivite durumudur. İyi şarkı söylemek için baş ve boyun rahat bir biçimde olmalı aynı zamanda göğüs geniş olmalıdır" (Bloem-Hubatka, 2012, s.38-39).

Bloem-Hubatka The Old Italian School of Singing adlı kitabında, günümüz şan tekniği ile eski dönem şan tekniği arasında farklılıklar bulunmakta olduğunu savunmuştur. Bloem-Hubatka, nefes ile ilgili farklılıkları şu şekilde ifade etmiştir. "Modern şarkı söyleme tekniklerinde ekspiratuar tekniği kullanılmaktadır. Ekspiratuar şarkı söylemek demek nefes ile ilerlemek nefes ile söylemek demektir. Modern şarkı söyleme tekniklerinde, her zaman nefes ile ilerlenmektedir. Nefes ile ilerlemek demek sesin nefesin akışında yüzmesi demektir. Eski dönem şarkı söyleme tekniğinde nefesin üzerinde şarkı söylemek geçerliydi, günümüz şarkı söyleme tekniğinde ise nefes ile şarkı söylemek geçerlilik kazanmıştır. Daha iyi örneklemek adına iki ok hayal edilebilir. Eski dönem şarkı söyleme tekniğinde, bir ok, larenksten göğüs kafesine doğru işaret ederken, diğer ok mideden göğüs kafesine işaret etmektedir. Günümüz şarkı söyleme tekniğinde ise, bir ok aşağı doğru diyaframı iterken, diğeri larenksi geçerek kafaya ulaşmaktadır. Sonuç olarak, ne- 
fesin akışı tonu, larenksin engeliyle karşılaşmadan kafaya doğru itmektedir” (Bloem-Hubatka, 2012, s.38-42).

Ünlü Amerikan şan pedagogu Richard Miller (1926-2009) Solution For Singers adlı kitabında, günümüz şan pegagojisinde, İtalyan terim appogionun ${ }^{3}$ bugünkü terim onseti ${ }^{4}$ getirdi- $^{-}$ ğini savunuyor. Ve nefes ile ilgili şu yorumlarda bulunuyor. "Appogio terimi İtalyanca destekle yaslanmak anlamına gelmektedir. Sanırım bu sepeble olsa gerek, bazı şan pedagogları nefese yaslanmak, nefesi tutmak gibi terimler kullanmaktadırlar. Başka bir yanlış kullanılan terim, nefesi tutmak terimidir. Nefesi tutmak terimi bilinçli olarak nefesi kesmeyi öneren çok talihsiz bir uyarıdır. Verimli bir nefes kullanımı bunun tam tersini gerektirir. Nefes alma başlangıcında, fonasyon sırasında, sesi çıkarma sırasında, yeni nefes alma sırasında nefes kesilmeden devam eder. Bir öğrenciye nefesi tut demek, doğru bir dil değildir, bu söz pedagojik sözlükten çıkmıştır" (Miller, 2004, s.18).

Bazı şan pedagogları, öğrenciye nefesi tarif ederken, günlük yaşamda olduğu gibi doğal nefes alması gerektiğini önermektedir. Amerikalı duayen şan pedagogu Richard Miller, kitabında bu konuyla ilgili şöyle demektedir. "Normal konuşma sırasındaki solunumda, nefes alma işlemi çok ender olarak 5 saniyenin üzerinde alınmaktadır. Shakespeare oyuncuları ve sunucular, bu süreyi uzatmayı öğrenirler. Fakat elit bir şarkıcının, uzun süren müzikal cümlelerde, her tessituradan $^{5}$ ve dinamikten söylemesi gerekmektedir. Bir şancının nefes kullanma idaresi konuşma sırasında kullanılan nefes kontrolüne göre çok daha üstün olması gerekmektedir” (Miller, 2004, s.18).

\section{6.Ünlü şan pedagoglarının nefes ile ilgili önerdiği bazı egzersizler}

Bir şancının enstrümanı bedenidir. İyi bir şancı, bedeninin farkında olan ve bedenini iyi tanıyan kişidir. Sesin ve nefesin nasıl oluştuğunu anatomik olarak bilmek çok önemlidir. Teorik olarak bilgi öğrenildikten sonra bedenin doğru nefes mekanizmasını otomatik olarak yapabilir hale gelebilmesi için nefes konusunda çalışma ve egzersizler yapmak gerekmektedir. Nefes geliştirilebilir? "Dr.Roth nefesi geliştirmek için şu egzersizleri önermektedir; "Dudaklarınızı hafif aralayarak, yavaş biçimde nefes alın ve serbest biçimde nefes verin. Serbest biçimde nefes alın ve yavaş bir şekilde nefes verin. Serbest biçimde nefes alın ve on saniye veya daha fazla nefesinizi tutmaya çalışın”. Nefes alırken yapılan en önemli hatalar, acele, hızlı, sesli nefes almak ve omuzları kaldırmaktır. Glottis, akciğerlerin etkisi altındadır. Ve akciğerlerden gelen havanın basıncını ayarlamak sesin oluşumu açısından çok önemlidir” (Garcia, 1894, s.4-5).

Richard Miller, nefesin nasıl alınması ve nasıl kullanılması gerektiği ile ilgili olarak şu ifadeleri kullanmaktadır. "Nefesin çok yavaş bir biçimde burundan alınmasını öneririm. Sessiz bir biçimde burundan alınan nefes, nefes kapasitesini tamamen doldurmaktadır. Ayrıca, burundan sessizce alınan nefes, ses rahatlığı da sağlamaktadır. Gırtlak ve dil rahat biçimde aşağıda durur ve zigomatik ${ }^{6}$ kaslar, yanağın bağ dokularını yukarı kaldırmaktadır. Bu yavaş ve derin nefes

3 Appogio: İtalyanca karşıllı̆̆ destek demektir, şan pedagojisinde, nefesin üzerinde şarkı söylemek demektir.

4 Onset: Şan pedagojisinde nefesin üzerinde temiz başlangıç sesi elde etmek demektir.

5 Tessitura: Ses aralığ 1

6 Zygomatic: Şakak kemiği 
alma, vokal bölge için ideal bir nefes alma yöntemidir. Gırtlak, abdominal duvarın kasları ve La lotta Vocale 'ye uygun zemin hazırlamaktadır. (Miller, 2004, s.20). La lotte iyi şan pegagoglarının üzerinde durduğu bir konudur. 1850 yıllarından itibaren Milano Konservatuarı’nda şan pedagogu olarak görev yapmış ve dünyaca ünlü opera sanatçıları yetiştirmiş Lamperti The

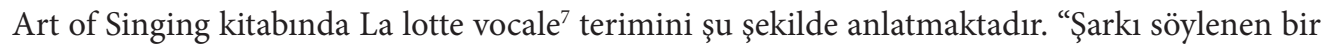
notayı tutmak için, nefes yavaş bir biçimde verilmelidir. Bunu elde etmek için, solunum kasları görevlerine devam ederken, akciğerlerdeki havayı korumaya gayret ederler ve expiratuar ${ }^{8}$ kaslara karşı olarak mücadele ederler. Buna la lotta vocale, vokal mücadele denmektedir". La lotte terimi, ne hava akışının aşırı olarak verilmesi ne de nefesin akışına karşı güçlü bir mücadeledir” (Miller, 2004, s.11).

Nefes çalışma egzersizleri düzenli olarak yapılmalıdır. Düzenli ve verimli çalışma yaparak iyi bir nefes kontrolüne sahip olunabilir. "Nefes kontrolü için beş nokta çok önemlidir; Sessiz başlangıç nefesi almak, cümleye temiz bir başlangıç sesi ile başlamak (onset), fonasyonun süresi (cümlenin uzunluğu), cümle sonunun temiz ve net bir şekilde bitirilmesi, sessiz bir biçimde yeni nefes almak" iyi şarkı söylemek için çalışılması gereken hususlardır” (Miller, 2004, s.31).

Garcia yanlış nefes almanın düzeltilmesi için yavaş ve derin bir biçimde nefes alınmasını önermektedir. "Yavaş ve derin bir biçimde nefes almak glotisin genişçe açılmasının sağlamaktadır. Hızlı, acele ve sesli nefes alındığında glottis, yarım açılmaktadır” (Garcia, 1894, s.4-5).

Nefes sessiz biçimde alınmalıdır. "Sessiz nefes alma egzersizleri appoggionun farkındalığını arttırmaktadır. Sessiz nefese Farinelli Nefesi denilmektedir. Farinelli, aldığı iyi ve sessiz nefes ile tanınmaktadır. Farinelli nefesi, dört bölümden oluşmaktadır. (1) Yavaş tempolu nefes almak; (2) Nefesi içinde tutmak; (3)Nefesin verilme sürecinin kontrolü; (4) Nefesin hızlıca yenilenme süreci. İçinizden dörde kadar sayın. Her sayı için bir saniye tutun. Egzersizin ilk bölmünde, yavaş tempolu sessiz nefes alın ve dörde kadar sayın. Daha sonra nefesi aldığınız pozisyonda (inspiratuar) kalın ve dörde kadar sayın. Nefesi verirken yine dörde kadar sayın. Bu sayıları yavaş yavaş arttırın. İdeal süre 10’a kadar saydığınız süre olacaktır ”(Miller, 2004, s.6).

"İkinci faydalı sessiz nefes egzersizi, tek bir nefes ile, kesik kesik (staccato) ve hızlı biçimde fonasyon olmadan sessiz harflerle verilen nefes çalışmasıdır. /s-s-s-s-s/. Bu çalışmayı sayısız şekilde tekrar ediniz. Üçüncü faydalı bir egzersiz ise, 5 adet mumu bir seferde söndürecekmiş gibi düşünerek hızlı bir biçimde /f-f-f-f-f/ sesi çıkararak yapılan nefes egzersizdir. Bu egzersiz de birçok kez tekrar edilmelidir. Dördüncü ses çıkarmadan yapılan sessiz nefes çalışmasında ise, genişleyerek nefes alınmalı ve /s/ sessiz harfi ile nefes verilmelidir. Bu egzersiz sırasında nefesinizi 20 saniye tutarak başlayınız ve yavaş yavaş süreyi arttırınız" (Miller, 2004, s.7-8).

"Her şarkıcının çalışması gereken nokta, cümlelerini bitirken sanki hayali başka notalar söyleyecekmiş gibi içeride yedek hava bulundurması gerektiğidir. Böylelikle, cümlenin sonuna kadar sesinin kalitesini korumakla kalmayacak, bir sonraki cümle için gerekli nefesi alırken hızlı bir biçimde alabilecektir" (Shakespeare, 1898, s.22).

7 La totta vocale: Şan pedagojisinde, vokal mücadele sözlük anlamına La lotta vocale, appogio nefes tekniğinin bir parçasıdır. Nefes alma pozisyonunu, nefes alma, nefes verme ve yeniden sessizce nefes alma strasinda koruma mücadelesidir. 8 Expiratuar: (expiratory): Nefes vermekle ilgili 


\section{SONUÇ}

Şarkı söylemek sadece ses kaslarıyla gerçekleştirilen bir eylem değildir. İyi bir teknik ile şarkı söyleyebilmek için, bedeni iyi tanımak ve sesin üretilme sürecini iyi bilmek gerekir. Bir şancının enstrümanı bedenidir. Bedeni serbest bırakmadan ve sesin kalitesini belirleyen nefesi doğru kullanmadan güzel şarkı söylemek mümkün değildir.

Bir şancının başarılı bir şan tekniğine sahip olabilmesi için beden rahatlı̆̆ı ve nefes gelişimi konuları üzerine çalışma ve egzersiz yapması gerekmektedir. Doğru nefes almamak veya bedeni rahat bırakmamak eklemler, omurga, nefes alma mekanizması ve diğer organlarda basınç yaratarak, tiz notaların sıkışık çıkmasına sebep olur. Bu zorlukların üstesinden gelebilmek için düzenli egzersiz yapmak çok önemlidir. Teknik zorluk yaşayan opera öğrencileri beden farkındalığı ve beden rahatlığı üzerine çalışmalı ve nefes mekanizmasını öğrenip, bununla ilgili egzersizler yapmalıdır.

Bu makale ile, iyi bir şan tekniğine sahip olmak için gerekli olan nefes tekniğini, dünyaca tanınan şan pedagoglarının nefes üzerine yazdığı kitap ve makaleler aracılı̆̆ıyla, şan dersi veren şan pedagoglara ve şan öğrencilerine ulaştırmak amaçlanmıştır. 


\section{KAYNAKÇA}

Cevanşir, B.-Gürel, G. (1982). Foniatri, İstanbul: İstanbul Üniversitesi Tip Fakültesi Yayınları,15.

Garcia, M. (1894). Hints on Singing, Ascherberg, Hopwood Crew Limited, New York, 4-5.

Bloem-Hubatka, D. (2012). The Old Italian School of Singing, McFarlandeCompany Publishers, North Carolina,38.

Linklater, K. (1976). Freeing the Natural Voice. New York: Drama Book Specialist

Miller, R. (2004). Solutions For Singers, Oxford University Press, 3,4,5,11,18,20,31.

Yıldırım, A. Ş., H. (2006). Sosyal Bilimlerde Nitel Araştırma Yöntemleri Seçkin Yayıncılık, 5. Basım, Ankara.

Shakespear, W. (1898). The Art of Singing Londra, 11-15, 22.

Süner, L. (2014). Ses ve Oyuncu Dergipark Akademik, Cilt 18, Sayı 18, 5.

Süner, L. (2011). Nefes ve Oyuncu Tiyatro Araştırmaları Dergisi, 31:2011/1 • ISSN: 1300-1523

Türk Dil Kurumu Sözlüğ̈̈, Erişim Tarihi: 03/01/2017 Ankara.

American Academy of Otolaryngology-Head and Neck Surgery,2015. http://www.entnet.org/content/how-voice-works Erişim Tarihi: 9/01/2017.

Human voice production www.voicefoundation.org, Erişim Tarihi: 03/02/2017.

How do we breathe? (www.blf.org.uk, Erşim Tarihi: 12/01/2017).

Diyafram kası nedir? (www.msxlabs.org, Erşim tarihi: 20/01/2017).

\section{Şekil Listesi}

Şekil 1. Ses kaslarının (vocal fold) vibrasyon strasındaki hareket diyagramı (Smith,2007:15)

Şekil 2.Akciğerler, Nefes Borusu (Trakea), Grrtlak (Larenks) (Garcia, 1894: 3)

Şekil 3. Diyafram Kasının Şekli (www.msxlabs.org, Erşim tarihi:20/01/2017) 


\section{ANADOLU ÜNIVERSITTESİ GÜZEL SANATLAR ENSTITÜSÜ HAKEMLI SANAT \& TASARIM DERGISII YAYIN İLKELERİ VE YAZIM KURALLARI}

\section{YAYIN İLKELERİ}

SANAT \& TASARIM dergisi, Anadolu Üniversitesi Güzel Sanatlar Enstitüsü tarafından yılda iki kez yayımlanır.

SANAT \& TASARIM dergisi, Güzel Sanatlar alanlarındaki bilimsel yazıları yayımlayan hakemli bir dergidir. Dergide yayımlanmak üzere Enstitüye gönderilen yazılar baş editör tarafından alan editörü olarak atanan kişiye gönderilir. Alan editörü, konunun uzmanı üç akademisyeni hakem olarak belirler, üç hakemden gelen raporların sonucunda en az iki hakemin olumlu görüşü üzerine alan editörü kendi tespitlerini de göz önünde bulundurarak değerlendirme raporunu enstitüye gönderir. Rapor sonunda olumlu bulunan makale doğrudan yayımlanma sürecine dahil edilir. Ancak editörün raporunda yazardan düzeltme istendiği takdirde düzeltmenin en geç 1 ay içinde yapılarak tekrar gönderilmesi gerekmektedir. Takibinde dergide yayımlanmak üzere yazar makalenin son halini yalnızca Word belgesi olarak göndermelidir.

Dergiye Plastik Sanatlar, Tasarım, Müzik, Sahne Sanatları gibi Güzel Sanatlar alanları ve bu alanların bilim dalları ile olan bağlantılarının işaret edildiği çalışmalar kabul edilir. Daha öncesinde başka dergi ya da dergilerde yayımlanmış, yayımlanmak için kabul edilmiş ve yayımlanmak için değerlendirilmekte olan yazılar değerlendirilmeye alınmaz.

Derginin dili Türkçe ve İngilizcedir. Makalenin İngilizce özetinde başlık, anahtar kelime ve yazarın künyesi mutlaka bulunmalıdır. İngilizce makalelerin Türkçe özetleri de olmalıdır.

Yayımlanan yazıların sorumluluğu tümüyle yazar /yazarlara aittir.

Derginin aynı sayısında bir yazara ait birden fazla makale yayımlanamaz.

Yazar tarafından önerilen yazı Güzel Sanatlar Enstitüsü Sekreterliğine elden, posta veya e-posta “sanattasarim@anadolu.edu.tr” yoluyla ulaştırılabilir. Basılmak üzere gönderilen ya da teslim edilen yazının Anadolu Üniversitesi Güzel Sanatlar Enstitüsü SANAT \& TASARIM Dergisinde yayımlanmak üzere önerildiğini ve türünün (Derleme, Araştırma Makalesi, Editöre Mektup veya Kitap Tanıtımı) belirtildiği bir dilekçe de ekinde yer almalıdır. Ayrıca yazar önerdiği yazının daha önce yayımlanmadığını, yayımlanmak üzere kabul edilmediğini ve halen başka bir yerde yayımlanmak üzere değerlendirme aşamasında olmadığını kabul etmiş sayılır. 


\section{Dergide aşağıda belirtilen özellikleri taşıyan yazılar yayımlanabilir:}

1.Derleme: Belli bir konuda yakın zamana kadar yapılmış bilimsel ve sanatsal çalışmaların kaynak olarak kullanıldığı kapsamlı çalışmalar.

2.Araştırma Makalesi: Özgün araştırmaları tanıtan ve sonuçlarını sunan bilimsel formatta yazılmış makaleler.

3.Editöre Mektup: Güzel Sanatlar Enstitüsü Hakemli Sanat \& Tasarım Dergisi’nde yayımlanmış yazılar ile ilgili yorum, eleştiri ve düzeltmeler.

4.Kitap Tanıtımı: Sanat alanında çıkmış kitapları tanıtmaya yönelik bilimsel formatta yazılmış yazılar.

\section{YAZIM KURALLARI}

1. Yazılar; Word programında A4 boyutunda, Times New Roman yazı karakteriyle 12 punto ve 1,5 satır aralıklı olarak yazılmalıdır. Sayfa kenar boşlukları; sağ kenar 3, sol kenar 2.5, üst kenar 4 , alt kenar $3 \mathrm{~cm}$ olacak şekilde ayarlanmalıdır. Sayfa numaraları sağ alt köşeye 10 punto olarak yazılmalıdır.

2. Yazının ilk sayfasında yazının başlı̆̆ı, yazarın/yazarların adları, akademik unvan/unvanları, kurum/kurumları, anasanat/anabilim dalı, metnin özeti ve anahtar sözcükler (en az 5, en çok 7) bulunmalıdır. Yazının ikinci sayfasında ilk sayfada yer alan tüm bilgilerin İngilizce çevirileri olmalıdır. Yazışmaların yapılacağı adres ise dipnot olarak belirtilmeli, yazarın posta adresi, telefon numarası ve e-posta adresi yazılmalıdır. Ayrıca ilk sayfada, varsa çalışmayı destekleyen kurum/kuruluşlar, vb. dipnot olarak belirtilmelidir.

3. Özet; derleme ve araştırma makaleleri için 100, editöre mektup ve kitap tanıtımı için ise 50 sözcügü aşmamalıdır. Özette, denklem, atıf, standart dışı kısaltmalar, vb. yer almamalıdır.

4. Yazı; şekil ve tablolar dahil 20 sayfayı, editöre mektup ise 5 sayfayı aşmamalıdır.

5. Notasyon ve kısaltmalar; ilgili sanat/bilim alanında bilinen standart notasyon ve kısaltmalar olmalı ve ilgili sayfada dipnot olarak verilmelidir.

6. Makalenin formatı; GİṘŞ, İLGILİ ALT KONU BAŞLIKLARI ve SONUÇ olarak oluşturulmalıdır.

7. Yazılarda kullanılmak istenen resim, fotoğraf, grafik, çizim, vb. görseller; 300 dpi çözünürlükte JPEG veya TIF formatında olmalıdır. Görsellerin künyesi hemen altında ve eksiksiz verilmelidir. Ayrıca görsel listesi ve görsellerin kaynak gösterimi, kaynakça sayfasında yer almalıdır.

8. Metin içinde başka eserlere yapılan atıflar, The American Psychological Association (APA) sistemi kullanılarak yapılmalıdır.

Kaynakça ve kaynak gösterimi hakkında detaylı bilgi ve örnekler için lütfen bkz.

http://www.gse.anadolu.edu.tr/duyurular/tez-yazim-kilavuzu 